\title{
Heat fluxes and electrodes temperature in a proton exchange membrane fuel cell
}

\author{
Anthony Thomas ${ }^{a}$, Gael Maranzana, Sophie Didierjean, Jérôme Dillet \\ AND OLIVIER LOTTIN \\ Université de Lorraine, LEMTA, UMR 7563, 54504 Vandoeuvre-lès-Nancy, France
}

Received 6 July 2012, Accepted 29 August 2012

\begin{abstract}
Measurement of heat fluxes and electrodes temperature in a proton exchange membrane fuel cell were performed using platinum wires and heat flux sensors. A temperature difference of $6{ }^{\circ} \mathrm{C}$ to $9{ }^{\circ} \mathrm{C}$ between the electrodes and the bipolar plates was observed for a cell operating at a current density of $1.5 \mathrm{~A} . \mathrm{cm}^{-2}$. These measurements show a strong non-uniformity of the temperature profile through the membrane electrode assembly that future models should take into account. Simultaneous heat fluxes measurements have allowed to evaluate in situ the effective thermal conductivity of the porous layers. Values of the order of $0.3 \mathrm{~W} \cdot \mathrm{m}^{-1} \cdot \mathrm{K}^{-1}$ were found.
\end{abstract}

Key words: Electrodes temperature / platinum wires / heat fluxes / fuel cell / PEMFC

\section{Introduction}

Proton Exchange Membrane Fuel Cells (PEMFC) make it possible to convert efficiently chemical energy into electrical energy. Using hydrogen as fuel, they can produce electricity over a wide range of power without on-site emission of greenhouse gases, the only reaction product being water. PEMFC are currently used for powering electric vehicles, portable electronic devices and cogeneration systems of small and medium power.

Despite recent technological advances, their largescale commercialization is still hampered by issues of cost (platinum catalyst and polymer membrane prices) and durability that can be related to water management within the cell (through electrode corrosion, dissolution of platinum, oxygen transport). The study of water transport in a proton exchange membrane fuel cell is therefore fundamental.

$50 \%$ to $70 \%$ of the energy exiting the cell as heat, the impact of the temperature field on water transport in the Membrane Electrodes Assembly (MEA) was therefore considered in recent works [1-10]. In 2002, Djilali and $\mathrm{Lu}$ [1] focused on the modeling of non-isothermal and nonisobaric effects (including Knudsen diffusion and Soret effects). They found a typical mean temperature difference of 1 to $5{ }^{\circ} \mathrm{C}$, between the bipolar plate and the cathode, function of the current density and thermo-physical properties of materials. Weber and Newman [2] and

\footnotetext{
a Corresponding author:

anthony . thomas@univ-lorraine.fr
}

Wang and Wang [3] showed, by considering the non-isothermal operation of fuel cells, that evaporation/condensation (i.e., heat pipe effect) through the porous layers may have a significant impact at high current densities. Eikerling [4] also showed that at a current density of $1 \mathrm{~A} . \mathrm{cm}^{-2}$, the evaporation rate at the electrode is sufficient to remove all water produced at the cathode in vapor phase.

Hickner et al. [5, 6], Kim and Mench [7, 8] and $\mathrm{Fu}$ et al. [9] used neutron radiography to visualize this phenomenon and they put forward the importance of evaporation at high current densities. The temperature is a significant parameter, in terms of water condensation/evaporation and considering the fluxes in vapour phase. Indeed, the works of Kim and Mench, Fu et al. or Hatzell et al. [10] showed that water goes preferentially towards the colder side of the fuel cell. Because of this phenomenon, it is important to realize accurate measurements of temperature in all parts of the cell.

Temperature measurements within an operating fuel cell have been already performed. In 2004, Vie and Kjelstrup [11] were the first to measure the local temperature near the electrodes using thermocouples $(120 \mu \mathrm{m}$ in diameter). By measuring the temperature at the membrane/electrode interface and channel/gas diffusion layer (GDL) interface, they estimated the thermal conductivity of the membrane and of the electrode+GDL. Zhang et al. $[12,13]$ used thermocouples with a diameter of $100 \mu \mathrm{m}$ that they placed at the GDL/electrode interface to measure the temperature difference between the air 
flow at the inlet and at the outlet of the cathode compartment. They observed a correlation between the local temperature and the local current density. A difference of $5{ }^{\circ} \mathrm{C}$ was measured between the electrode and the bipolar plate for a current density of $1 \mathrm{~A} \cdot \mathrm{cm}^{-2}$. A correlation between local temperature, current density and the presence of liquid water was also put forward by Maranzana et al. [14] using a segmented and transparent fuel cell; the temperature measurement was done using thermocouples inserted along the air channels.

To complement these studies and provide data for future models, these works consisted in measuring the internal temperatures in a proton exchange membrane fuel cell using small platinum wires, which diameters are more adapted to the electrode thickness than that of (most of) electrically insulated thermocouples. Beside, heat fluxes are measured on the anode and cathode sides.

\section{Experimental set up}

A hydrogen fuel cell is a cell in which the electrical power is obtained by hydrogen oxidation at the anode and oxygen reduction at the cathode. For this, a membrane electrode assembly (MEA) is sandwich between porous layers (to obtain a homogeneous diffusion of gases over the entire surface of the electrodes) and bipolar plates which ensure the supply of hydrogen and air.

The MEA considered for this experiment consists of a $30 \mu \mathrm{m}$ perfluorosulfonated membrane and two $10 \mu \mathrm{m}$ thick electrodes with a platinum loading of $0.2 \mathrm{mg} . \mathrm{cm}^{-2}$ at the anode and $0.6 \mathrm{mg} . \mathrm{cm}^{-2}$ at the cathode. The surface of the MEA is $5 \times 5 \mathrm{~cm}^{2}$. Hydrogen and air flow in bipolar plates consist of 28 parallel channels of $50 \mathrm{~mm}$ in length, $1 \mathrm{~mm}$ in width and $0.4 \mathrm{~mm}$ in depth. To obtain a homogeneous diffusion of gases toward the entire surface of electrodes, $375 \mu \mathrm{m}$ thick porous layers made of carbon fibers coated with 5\% PTFE (Gas Distribution Layer - GDL) and $45 \mu \mathrm{m}$ thick strongly hydrophobic (30\% PTFE) MicroPorous Layers (MPL) are inserted between the plates and the active layers.

The scheme of the experimental setup is shown in Figure 1. At the inlet of the cell, hydrogen and air are preheated and humidified using bubblers which temperature was set to $60{ }^{\circ} \mathrm{C}$.

At the outlet, gases pass through a condenser maintained at $8{ }^{\circ} \mathrm{C}$ using a Peltier module. The condensed water is weighed using scales with an accuracy of $0.01 \mathrm{~g}$. The water balance between the input and the output of the anode and cathode compartment is used to estimate the mean water fluxes through the porous layers and the membrane, perpendicularly to the MEA surface.

Simultaneously, the heat fluxes through the cell are measured using two sensors placed between thermoregulated aluminum plates and the bipolar plates. The temperature of the plates is assumed equal to that of water flowing through the aluminum plates.

For measuring the temperature of the electrodes, eight platinum wires are inserted at the electrode/MPL interface (Fig. 2). The Pt wires diameter is $35 \mu \mathrm{m}$ including a

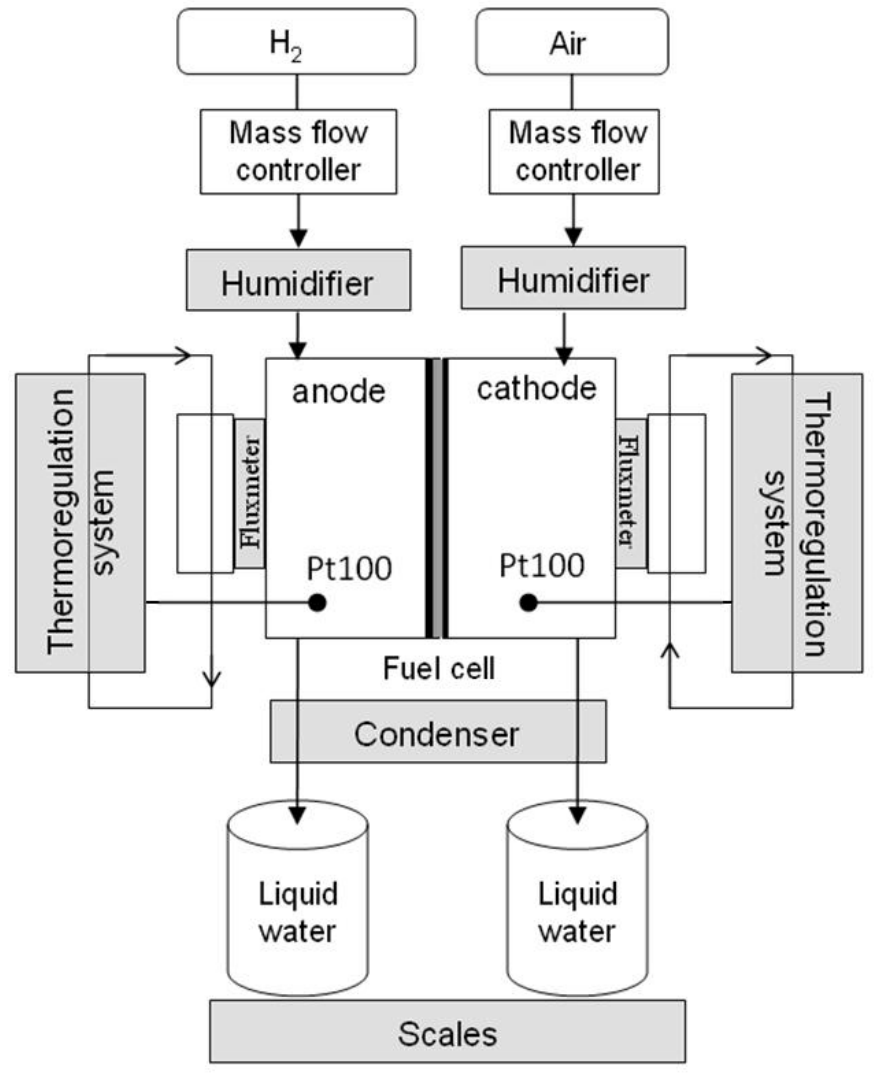

Fig. 1. Scheme of the experimental setup.

$5 \mu \mathrm{m}$ Kapton coating, which is $2-3$ times larger than the average diameter of carbon fibers constituting the GDL. These wires are manually placed at $1 \mathrm{~cm}$ from each other. Consequently, we measure the average temperature perpendicularly to the gas flow or in other words, locally along the gas flow direction.

\section{Measurement protocols}

\subsection{Temperature measurement protocol}

The temperature measurement is based on the dependence of the electrical resistance of the platinum wires with the temperature. To obtain the resistance of each wire, a calibration is performed. This operation consists in setting the bipolar plate temperatures at identical values, varying between $57^{\circ} \mathrm{C}$ and $63^{\circ} \mathrm{C}$ the cell not being in operation. Figure 3 shows the variation with temperature of the voltage between both terminals of six of the eight platinum wires (two wires - Ta1 and Tc1 - had been broken during the compression and/or the heating of the plate) in the presence of a $25 \mathrm{~mA}$ direct current. Measuring this voltage during the fuel cell operation makes it possible to obtain the average temperature along each wire. It varies linearly with the temperature and the reproducibility of the measurement is good for 5 wires $(T a 2$ Ta3 Ta4 Tc3 and Tc4); Tc2 being not reproducible does not appear in the results. 


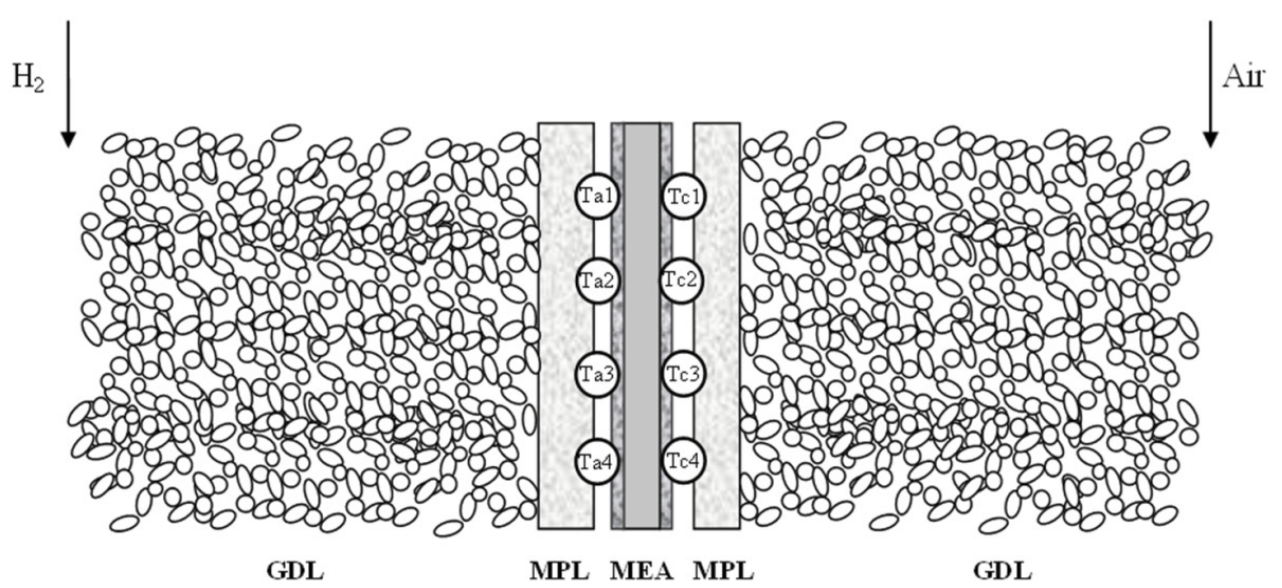

Fig. 2. Position of the eight wires at the electrode/MPL interface. Gases flow from top to bottom.

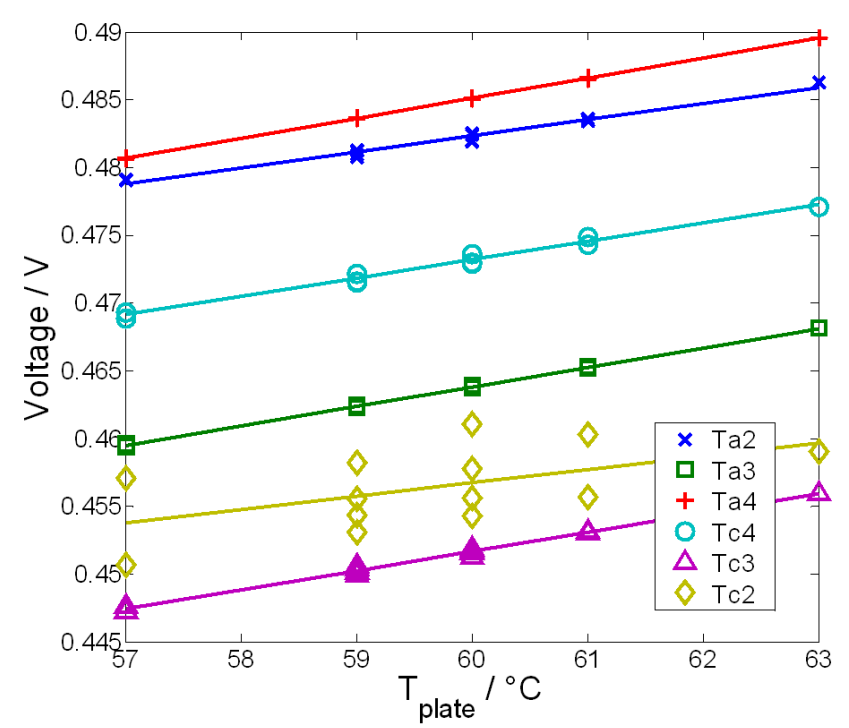

Fig. 3. Voltage wire measurements during the calibration.

\subsection{Heat flux measurement protocol}

Tangential gradient heat flux sensors deliver a voltage proportional to the incident heat flux. After a calibration stage, the proportionality coefficient (i.e., the sensor sensitivity) was found to be equal to $27.8 \pm 3 \% \mu \mathrm{V} \cdot \mathrm{W}^{-1} \cdot \mathrm{m}^{2}$ at the anode side and $23.2 \pm 3 \% \mu \mathrm{V} . \mathrm{W}^{-1} \cdot \mathrm{m}^{2}$ at the cathode side. The surface of the sensors is equal to $36 \mathrm{~cm}^{2}$. To obtain the heat flux through the porous layers, corrections are made on the raw flux measurements. These corrections take account of:

- heat losses due to the imperfect insulation (about $1 \mathrm{~W}$ per plate at $I=0 \mathrm{~A}$ );

- incoming heat fluxes provided by the overheated gases, as functions of mass flows and temperatures;

- and heat production associated with water condensation within the cell: hydrogen and oxygen consumption makes the vapour partial pressure increase along the gas channels, which is at the origin of water condensation that must be considered in the global enthalpy balance.

\section{Results and discussion}

All measurements presented below were performed with a stoichiometry of 1.4 for hydrogen and 3 for air and in a current densities range from 0.04 to $1.5 \mathrm{~A} . \mathrm{cm}^{-2}$. Three thermal configurations are studied:

(i) Identical temperature $-60{ }^{\circ} \mathrm{C}$ - for both plates $(\mathrm{Ta}$ at the anode and $T c$ at the cathode).

(ii) The temperature of the cathode plate is set to $62.5^{\circ} \mathrm{C}$ while that of the anode is equal to $57.5^{\circ} \mathrm{C}$.

(iii) The temperature of the anode plate is set to $62.5^{\circ} \mathrm{C}$ while that of the cathode is set to $57.5^{\circ} \mathrm{C}$.

As the bubblers temperature is kept equal to $60{ }^{\circ} \mathrm{C}$, the inlet relative humidities at the anode $\left(R H_{a}\right)$ and at the cathode $\left(R H_{c}\right)$ are strictly equal to $100 \%$. When Tc $>\mathrm{Ta}, R H_{a}=89 \%$ at the anode inlet and $R H_{c}=$ $100 \%$ at the cathode inlet; conversely, when $\mathrm{Ta}>\mathrm{Tc}$, $R H_{a}=100 \%$ and $R H_{c}=89 \%$. These thermal configurations were chosen to keep a constant average temperature of $60{ }^{\circ} \mathrm{C}$, which is representative of the nominal operating temperature of PEMFC for most of the applications.

\subsection{Electrodes temperature measurement}

Temperatures measured at the electrodes are shown in Figure 4 for fives platinum wires, Ta2, Ta3, Ta4, Tc3, and Tc4 (cf. Fig. 2) as functions of the current density and for the three thermal configurations of the bipolar plates described above.

In all cases, one can observe that the electrode temperature can be up to $9{ }^{\circ} \mathrm{C}$ higher than that of the bipolar plates (for a current density $j$ equal to $1.5 \mathrm{~A} . \mathrm{cm}^{-2}$ ), which corresponds to an average temperature gradient through the MEA of about $20 \mathrm{~K} \cdot \mathrm{mm}^{-1}$. Most of the heat sources in a PEMFC are increasing functions of the current density [15], and the electrode temperature varies 

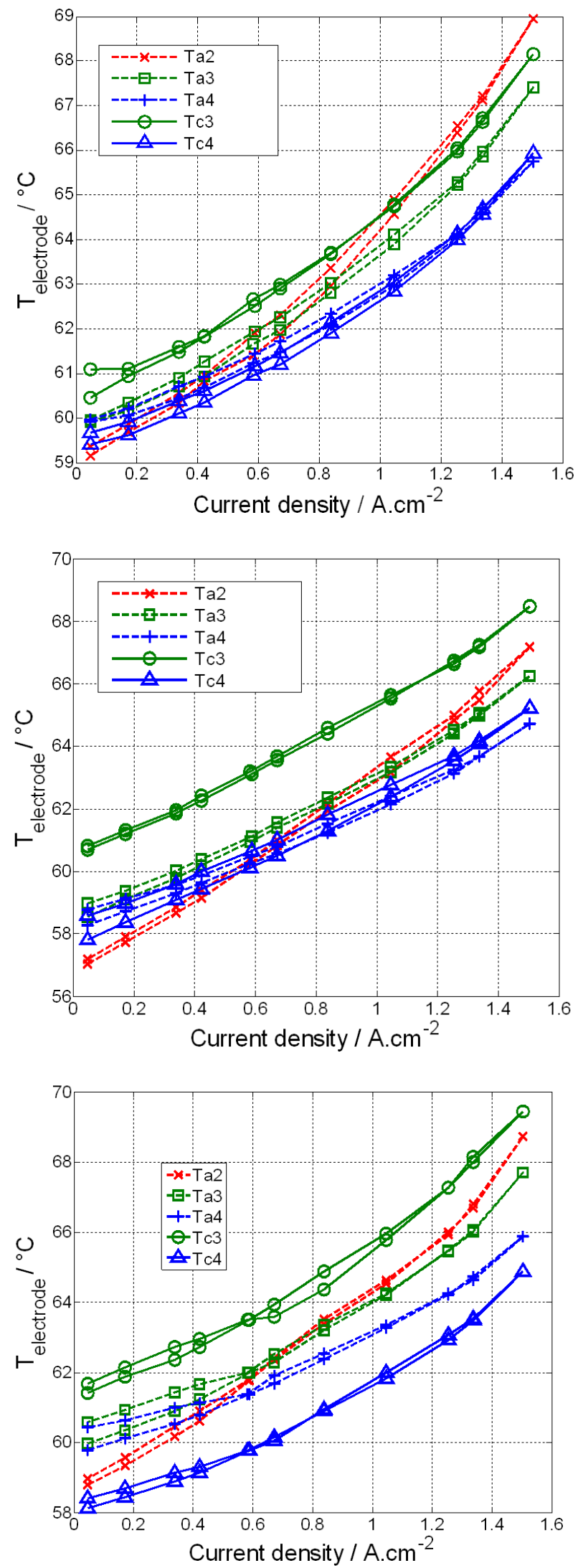

Fig. 4. Local electrode temperature measurements $\left({ }^{\circ} \mathrm{C}\right)$ vs. current density. (i) $T_{c}=T_{a}=60{ }^{\circ} \mathrm{C}+$ (ii) $T_{c}=62.5{ }^{\circ} \mathrm{C}>$ $T_{a}=57.5{ }^{\circ} \mathrm{C}+$ (iii) $T_{a}=62.5{ }^{\circ} \mathrm{C}>T_{c}=57.5{ }^{\circ} \mathrm{C}$. accordingly. One can notice the good reproducibility of the temperature measurements. The same kind of results was observed by Weber and Hickner [16] in the case of equal temperature bipolar plates: they measured a difference of $6^{\circ} \mathrm{C}$ between the plates and the electrodes at $j=1.25 \mathrm{~A} . \mathrm{cm}^{-2}$ with MEA made of equivalent materials (similar membrane and porous layers thicknesses).

A closer look at the results shows that when $T c=T a$ (Fig. 4i), the temperature difference varies between 6 to $9{ }^{\circ} \mathrm{C}$ for $j=1.5 \mathrm{~A} . \mathrm{cm}^{-2}$, depending on the position of the wire. It can be noted that the largest temperature difference is given by Ta2, located $2 \mathrm{~cm}$ from the gas inlet. This behavior can be explained by a higher local current density near the gas inlet than near the outlet where higher amounts of liquid water and vapour are generally observed, which limits the local fuel cell performances, especially at high current density.

When $T c>T a$ (Fig. 4ii), there is a similar increase in temperature as a function of $j$. However compared to the case (i), a decrease of $1^{\circ} \mathrm{C}$ is found throughout the range of current density, for Ta2, Ta3, Ta4 and Tc4. This can be explained at the anode side by a decrease of the bipolar plate temperature and at the cathode side by the appearance of water near the outlet of the cell.

When $T a>T c$ (Fig. 4iii), temperatures at the anode side - Ta2, Ta3, Ta4 - are very close to those measured in case (i). Compared to case (ii) the value of Tc3 increases by $0.5{ }^{\circ} \mathrm{C}$ and $T c 4$ stays the same. The trends of the curves are however preserved.

These measurements show a strong non-uniformity of temperature within the cell: considering it as isothermal is not justified.

\subsection{Heat fluxes measurement through the porous layers}

Figure 5 shows heat fluxes measurements through the porous layers, $\phi_{a}$ at the anode side in blue and $\phi_{c}$ at the cathode side in green. Heat fluxes are considered positive when directed from the source (MEA) to the outside.

As expected, the heat fluxes increase with the current density. More specifically, when $T c=T a$ (Fig. 5i), they are positive on both side, that is to say directed from the MEA to the ambient. The heat flux measured at the cathode side is higher than at the anode side, which can be explained by the condensation of more water at the cathode than at the anode.

When $T c>T a$ (Fig. 5ii), $\phi_{a}$ is always positive. $\phi_{c}$ is first negative, directed from the plate to the MEA, and becomes then positive due to the reversal of the temperature gradient. Indeed, the temperature at the cathode becomes higher than that of the bipolar plate $\left(T c=62.5^{\circ} \mathrm{C}\right)$ for a current density higher than $0.8 \mathrm{~A}^{-\mathrm{cm}^{-2}}$ (Fig. 4ii).

Conversely, when $T a>T c$ (Fig. 5iii) $\phi_{c}$ is always positive while $\phi_{a}$ changes of direction due to the reversal of the temperature gradient at the anode side, for a current density higher than 0.8 A.cm ${ }^{-2}$ (Fig. 4iii). 

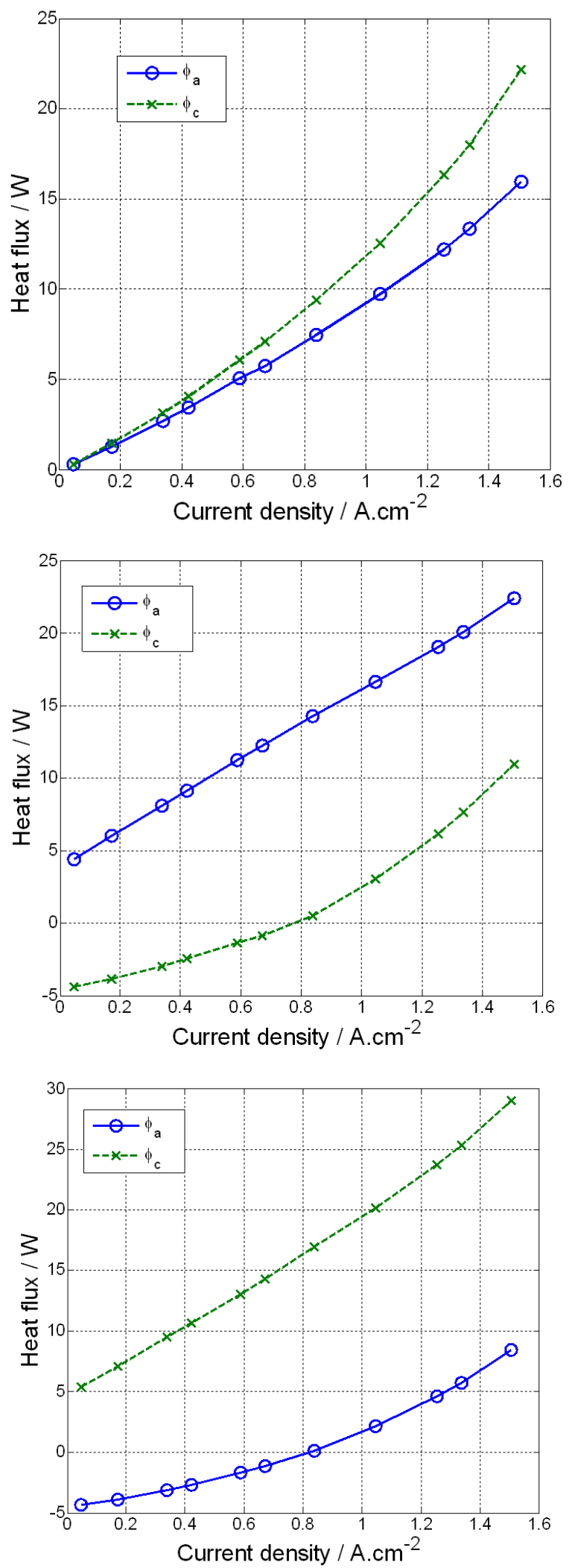

Fig. 5. Heat fluxes measurements at the anode $\left(\phi_{a}\right)$ and at the cathode $\left(\phi_{c}\right)$ vs. current density. By convention, heat fluxes are considered positive when they are directed from the source (MEA) to the outside. (i) $T_{c}=T_{a}=60{ }^{\circ} \mathrm{C}+$ (ii) $T_{c}=$ $62.5{ }^{\circ} \mathrm{C}>T_{a}=57.5{ }^{\circ} \mathrm{C}+$ (iii) $T_{a}=62.5{ }^{\circ} \mathrm{C}>T_{c}=57.5{ }^{\circ} \mathrm{C}$.

\subsection{Estimation of effective thermal conductivity of porous layers}

Thanks to the simultaneous temperature and heat flux measurements, it is possible to estimate in-situ the effective thermal conductivity of the porous layers (MPL + GDL). Indeed, by means of an electrical analogy and assuming conductive heat transfer in the direction perpendicular to the MEA, a thermal resistance relates the heat flux through the porous layer to the temperature difference on each side: $\Delta T=R \Phi$. The resistance depending on the material conductivity, its thickness and its surface $(R=e /(\lambda S))$, it is possible to estimate the thermal conductivity $\lambda$. However, it is necessary to consider the condensation of water in the gas channels and to subtract the corresponding heat sources from the measured heat fluxes: $\Phi_{a}=\phi_{a}-N_{a} L v$ and $\Phi_{c}=\phi_{c}-N_{c} L v$ (where the condensed water fluxes $N_{a}$ and $N_{c}$ were obtained thanks to a mass balance [17]). The results show that the effective thermal conductivity of the porous layers is equal to $0.3 \pm 0.2 \mathrm{Wm}^{-1} \cdot \mathrm{K}^{-1}$ on both sides and for the three thermal cases. The temperature values considered here are the average ones at each electrode, i.e. $\bar{T} e a=(T a 3+T a 4) / 2$ and $\bar{T} e c=(T c 3+T c 4) / 2$, assuming that only the temperatures measured simultaneously on both sides are relevant. This assumption implies an error of $\pm 0.65{ }^{\circ} \mathrm{C}$ on the average electrode temperature. Similar values of the through-plane thermal conductivity were found by Burheim et al. [18] with a $210 \mu \mathrm{m}$ thick GDL and in dry condition, with a compaction pressure of 9.3 bars. The same order of magnitude was also found by Ramousse et al. [19] using a standard ex-situ hot plate method.

\section{Conclusion}

Temperature measurements at the electrode were performed using platinum wires inserted at the electrode/MPL interface. The variation of the electrodes temperatures as functions of the current density was measured for three thermal configurations. A temperature rise of $9{ }^{\circ} \mathrm{C}$ between the electrodes and the flow field plates was measured for a current density of $1.5 \mathrm{~A} . \mathrm{cm}^{-2}$, demonstrating the existence of strong temperature gradients during the cell operation. Fuel cell modelling cannot consider isothermal water transport: the spatial variation of temperature needs to be taken into account. Concomitant measurements of water and heat fluxes allowed estimating in situ the effective thermal conductivity of the porous layers (MPL + GDL). Values of the order of $0.3 \mathrm{Wm}^{-1} . \mathrm{K}^{-1}$ were measured. According to the existing bibliography, it should be stated that it is the first time that simultaneous measurements of heat fluxes and electrodes temperature are published.

\section{References}

[1] N. Djilali, D. Lu, Influence of heat transfer on gas and water transport in fuel cells, Int. J. Therm. Sci. 41 (2002) $29-40$ 
[2] A.Z. Weber, J. Newman, Coupled thermal and water management in polymer electrolyte fuel cells, J. Electrochem. Soc. 153 (2006) A2205-A2214

[3] Y. Wang, C.Y. Wang, A nonisothermal, two-phase model for polymer electrolyte fuel cells, J. Electrochem. Soc. 153 (2006) A1193-A1200

[4] M. Eikerling, Water management in cathode catalyst layers of PEM fuel cells, J. Electrochem. Soc. 153 (2006) E58-E70

[5] M.A. Hickner, N.P. Siegel, K.S. Chen, D.S. Hussey, D.L. Jacobson, M. Arif, Understanding liquid water distribution and removal phenomena in an operating PEMFC via neutron radiography, J. Electrochem. Soc. 155 (2008) B294-B302

[6] M.A. Hickner, N.P. Siegel, K.S.Chen, D.S. Hussey, D.L. Jacobson, M. Arif, In situ high-resolution neutron radiography of cross-sectional liquid water profiles in proton exchange membrane fuel cells, J. Electrochem. Soc. 155 (2008) B427-B434

[7] S. Kim, M.M. Mench, Investigation of temperaturedriven water transport in polymer electrolyte fuel cell: Phase-change-induced flow, J. Electrochem. Soc. 156 (2009) B353-B362

[8] S. Kim, M.M. Mench, Investigation of temperaturedriven water transport in polymer electrolyte fuel cell: Thermo-osmosis in membranes, J. Membr. Sci. 328 (2009) 113-120

[9] R.S. Fu, J.S. Preston, U. Pasaogullari, T. Shiomi, S. Miyazaki, Y. Tabuchi, D.S. Hussey, D.L. Jacobson, Water transport across a polymer electrolyte membrane under thermal gradients, J. Electrochem. Soc. 158 (2011) B303B312

[10] M.C. Hatzell, A. Turhan, S. Kim, D.S. Hussey, D.L. Jacobson, M.M. Mench, Quantification of temperature driven flow in a polymer electrolyte fuel cell using highresolution neutron radiography, J. Electrochem. Soc. 158 (2011) B717-B726
[11] P.J.S. Vie, S. Kjelstrup, Thermal conductivities from temperature profiles in the polymer electrolyte fuel cell, Electrochim. Acta 49 (2004) 1069-1077

[12] G. Zhang, L. Guo, L. Ma, H. Liu, Simultaneous measurement of current and temperature distributions in a proton exchange membrane fuel cell, J. Power Sources 195 (2010) 3597-3604

[13] G. Zhang, S. Shen, L. Guo, H. Liu H, Dynamic characteristics of local current densities and temperatures in proton exchange membrane fuel cells during reactant starvations, Int. J. Hydrogen Energy 37 (2012) 1884-1892

[14] G. Maranzana, O. Lottin, T. Colinart, S. Chupin, S. Didierjean, A multi-instrumented polymer exchange membrane fuel cell: Observation of the in-plane nonhomogeneities, J. Power Sources 180 (2008) 748-754

[15] J. Ramousse, O. Lottin, S. Didierjean, D. Maillet, Heat sources in Proton Exchange Membrane (PEM) fuel cells, J. Power Sources 192 (2009) 435-441

[16] A.Z. Weber, M.A. Hickner, Modeling and highresolution-imaging studies of water-content profiles in a polymer-electrolyte-fuel-cell membrane-electrode assembly, Electrochim. Acta 53 (2008) 7668-7674

[17] A. Thomas, G. Maranzana, S. Didierjean, J. Dillet, O. Lottin, Thermal effect on water transport in proton exchange membrane fuel cell, Fuel Cells 12 (2012) 212-224

[18] O. Burheim, J.G. Pharoah, H. Lampert, P.J.S. Vie, S. Kjelstrup, Through-plane thermal conductivity of pemfc porous transport layers, J. Fuel Science \& Technology 8 (2011) 021013

[19] J. Ramousse, S. Didierjean, O. Lottin, D. Maillet, Estimation of the effective thermal conductivity of carbon felts used as PEMFC Gas Diffusion Layers, Int. J. Therm. Sci. 47 (2008) 1-6 